MSC 35C09, 35Q35

DOI: $10.14529 / \mathrm{mmp} 210102$

\title{
ANALYTICAL STUDY OF THE MATHEMATICAL MODEL OF WAVE PROPAGATION IN SHALLOW WATER BY THE GALERKIN METHOD
}

E. V. Bychkov, South Ural State University, Chelyabinsk, Russian Federation, bychkovev@susu.ru

\begin{abstract}
Of concern is an initial-boundary value problem for the modified Boussinesq equation (IMBq equation) is considered. The equation is often used to describe the propagation of waves in shallow water under the condition of mass conservation in the layer and taking into account capillary effects. In addition, it is used in the study of shock waves. The modified Boussinesq equation belongs to the Sobolev type equations. Earlier, using the theory of relatively p-bounded operators, the theorem of existence and uniqueness of the solution to the initial-boundary value problem was proved. In this paper, we will prove that the solution constructed by the Galerkin method using the system orthornormal eigenfunctions of the homogeneous Dirichlet problem for the Laplace operator converges *-weakly to an precise solution. Based on the compactness method and Gronwall's inequality, the existence and uniqueness of solutions to the Cauchy-Dirichlet and the Showalter-Sidorov-Dirichlet problems for the modified Boussinesq equation are proved.

Keywords: modified Boussinesq equation; Sobolev type equation; initial-boundary value problem; Galerkin method; *-weak convergence.
\end{abstract}

\section{Introduction}

Let $\Omega \subset \mathbb{R}^{n}$ be a domain with the boundary $\partial \Omega$ of class $C^{\infty}$ and $T \in \mathbb{R}_{+}$. In the cylinder $C=\Omega \times(0, T)$, consider the modified Boussinesq equation

$$
(\lambda-\Delta) u_{t t}-\alpha^{2} \Delta u+u^{3}=0, \quad(x, t) \in \Omega \times(0, T)
$$

with homogeneous Dirichlet boundary condition

$$
u(x, t)=0, \quad(x, t) \in \partial \Omega \times(0, T)
$$

and initial Cauchy conditions

$$
u(x, 0)=u_{0}(x), \quad u_{t}(x, 0)=u_{1}(x), \quad x \in \Omega,
$$

where $\lambda, \alpha \in \mathbb{R}$. The equation has many applications in various fields of natural science. For example, it simulates wave propagation in shallow water, taking into account capillary effects. In this case, the function $u=u(x, t)$ determines the wave height. In monograph [1] a linear mathematical model of wave propagation in shallow water is constructed. A (modified) mathematical model of wave propagation in shallow water in a one-dimensional region was investigated in [2] and a soliton solution of equation (1) was obtained. The existence of a unique global solution to the Cauchy problem for equation (1) was proved 
[3] for $\lambda=1, \alpha=1$. In [4], a similar solution was obtained for describing the interaction of shock waves.

The following generalized Pochhammer-Cree equation was considered in [2]

$$
u_{t t}-u_{t t x x}-(f(u))_{x x}=0,
$$

where $f(u)$ is a rational function of $u$. This equation is used to describe the propagation of a longitudinal strain wave in an elastic rod. In [1] and [2], a solution in the form of solitary waves for the Pochhammer-Cree equation

$$
u_{t t}-u_{t t x x}-u_{x x}-\frac{1}{p}\left(\left(u^{p}\right)\right)_{x x}=0
$$

with $p=2,3,5$ was constructed and was numerically investigated the interaction of two solitary wave solutions. For $f(u)=a_{1} u+a_{2} u^{2}+a_{3} u^{3}$ and $f(u)=a_{1} u+a_{3} u^{3}+a_{5} u^{5}$ in [5], explicit solitary wave solutions of the last equation were obtained using method of reduction to an algebraic equation. The bifurcation behavior of the phase portraits for the corresponding traveling wave equation was also investigated. Under various parametric conditions, all explicit formulas for solutions with a solitary wave and solutions with a kink wave were obtained in [6]. Also in [6], an initial-boundary value problem for the generalized Pochhammer-Cree equation

$$
u_{t t}-u_{x x}-u_{x x t}-u_{x x t t}=(f(u))_{x x}
$$

where $f$ is a non-decreasing function from $\left\{f \in C^{k+1}(R): f(0)=0\right\}$ was studied. Under an additional condition on $f(u)$ the authors proved the existence of a global solution.

In all the works listed above, an essential condition is the continuous invertibility of the operator at the highest derivative with respect to $t$. However, the operator $\lambda-\Delta$ can be degenerate. Equations that are not solvable with respect to the highest time derivative, according to [7] are called Sobolev type equations.

Using the theory of $p$-bounded operators developed by G.A. Sviridyuk and his disciples $[8,9]$, it was shown in [10] that in appropriately chosen spaces the problem (1) - (3) can be reduced to the initial value problem

$$
u(0)=u_{0}, \quad \dot{u}(0)=u_{1}
$$

for an abstract semilinear second-order Sobolev type equation

$$
L \ddot{u}-M u+N(u)=0,
$$

where $\dot{u}, \ddot{u}$ are the first and the second derivatives with respect to $t, L=\lambda-\Delta, M=$ $\alpha^{2} \Delta, N(u)=u^{3}$. Then, using the phase space method, a theorem on the existence of a unique local solution was proved. It was also noted that in the case of monotonicity of the operator $N$, the phase space would be a simple manifold.

Equation (1) belongs to the class of high-order Sobolev type equations [11, 12]. Sobolev type equations are closely related to algebraic-differential equations [13, 14]. Nowadays, more and more often the theory of Sobolev type equations is transferred from bounded domains in the space $\mathbb{R}^{n}$ to geometric graphs [15] and to the space of differentiable $k$-forms on Riemannian manifolds [16]. Many physical phenomena [17-19], as well as technical and 
economic processes [20] are modelled using Sobolev type equations. This explains the enduring interest in them.

The paper is structured as follows, firstly we introduce some preliminary information, then we investigate the existence of a solution to (1) - (3) using the Galerkin and compactness methods [21]. In the next section, we prove the uniqueness of the solution based on the embedding theorem and Gronwall's inequality. In conclusion, a remark about the Showalter-Sidorov problem and a recommendation for choosing a system of basis functions are made.

\section{Preliminary Statements}

Definition 1. Let $X$ be some Banach space, $X^{*}$ the dual space for $X$ with respect to the duality $\langle\cdot, \cdot\rangle$. The sequence $f_{n} \in X^{*}$ is called weakly-* converge to $f \in X^{*}$, if for any $g \in X,\left\langle f_{n}, g\right\rangle \rightarrow\langle f, g\rangle$ for $n \rightarrow \infty$.

Generally speaking, *-weak convergence is weaker than ordinary weak convergence, however, if $X$ is a reflexive Banach space, then *-weak and weak convergence are equivalent.

Lemma 1. [21] Let $O$ be a bounded domain in $\mathbb{R}_{x}^{n} \times \mathbb{R}_{t}, g_{l}$ and $g$ be functions from $L^{q}(O)$, $1<q<\infty$ such that

$\left\|g_{l}\right\|_{L^{q}(O)} \leq C, g_{l} \rightarrow g$ a.e. in $L^{q}(O)$.

Then $g_{l} \rightarrow g$ weakly in $L^{q}(O)$.

Lemma 2. (Courant Principle) Let $H$ be a separable Hilbert space of nonzero dimension and the operator $A: H \rightarrow H$ be a linear compact self-adjoint one. Since all eigenvalues of $A$ are real and finite-multiple, they can be numbered non-decreasingly

$$
\lambda_{-1} \leq \lambda_{-2} \leq \cdots \leq \lambda_{-n} \ldots \lambda_{n} \leq \cdots \leq \lambda_{2} \leq \lambda_{1} .
$$

Then, for any $n \geq 1$, the following relations hold:

$$
\begin{gathered}
\lambda_{n}=\inf _{H_{n-1}} \sup _{\substack{x \perp H_{n-1} \\
x \neq 0}} \frac{(A x, x)}{\|x\|^{2}}, \\
\lambda_{-n}=\sup _{H_{n-1}} \inf _{\substack{x \perp H_{n-1} \\
x \neq 0}} \frac{(A x, x)}{\|x\|^{2}},
\end{gathered}
$$

where $H_{n-1}$ is an arbitrary $(n-1)$-dimensional subspace in $H$.

Lemma 3. [21] If $f \in L^{p}(0, T ; X)$ and $\dot{f} \in L^{p}(0, T ; X), 1 \leq p \leq \infty$ ( $X$ is a Banach space), then $f$, after perhaps changing on the set from the interval $(0, T)$ with zero measure, is a continuous mapping from $[0, T]$ to $X$.

Lemma 4. (Gronwall's lemma [22]) Let $g(t) \geq 0$ and $f(t) \geq 0$ for $t \geq t_{0}$, and also $g, f \in C\left[t_{0},+\infty\right]$, and for $t \geq t_{0}, c>0$ the inequality

$$
g(t) \leq c+\int_{t_{0}}^{t} f(s) g(s) d s
$$


be satisfied. Then the inequality

$$
g(t) \leq c e^{\int_{t_{0}}^{t} f(s) d s}
$$

holds. Moreover, if $c=0$, then $g(t)=0$.

Lemma 5. (The Rellich-Kondrashov embedding theorem [23]) Let $\Omega \subset \mathbb{R}^{n}$ be a domain with a boundary of the class $C^{s}, s \geq 1, s>l, 1<p \leq q<\infty, s-\frac{n}{p} \geq l-\frac{n}{q}$. Then

$$
W_{p}^{s}(\Omega) \subset W_{q}^{l}(\Omega) \text { completely continuous (compact). }
$$

Earlier, problem (4), (5) was studied by the methods of $p$-bounded operators theory. Let $X, Y$ be Banach spaces, the operator $L \in \mathcal{L}(X ; Y)$ (i.e., linear and continuous), and the operator $M \in \mathcal{C} \mathcal{L}(X ; Y)$ (linear and densely defined). The set

$$
\rho^{L}(M)=\left\{\mu \in \mathbb{C}:(\mu L-M)^{-1} \in \mathcal{L}(Y ; X)\right\}
$$

is called the resolvent set of the operator $M$ with respect to the operator $L$ (or, the $L$ resolvent set of the operator $M)$. The set $\mathbb{C} \backslash \rho^{L}(M)=\sigma^{L}(M)$ is called the spectrum of the operator $M$ with respect to the operator $L$ (or, the $L$-spectrum of the operator $M$ ).

Operator functions $(\mu L-M)^{-1}, R_{\mu}^{L}=(\mu L-M)^{-1} L, L_{\mu}^{L}=L(\mu L-M)^{-1}$ with the domain $\rho^{L}(M)$ are called, respectively, resolvent, right resolvent, left resolvent of the operator $M$ with respect to the operator $L$ (in short, L-resolvent, right L-resolvent, left $L$-resolvent of the operator $M)$.

An operator $M$ is called $(L, \sigma)$-bounded if

$$
\exists a>0 \forall \mu \in \mathbb{C}:(|\mu|>a) \Rightarrow\left(\mu \in \rho^{L}(M)\right) .
$$

Let the operator $M$ be $(L, \sigma)$-bounded. Then the operators

$$
P=\frac{1}{2 \pi i} \int_{\Gamma} R_{\lambda}^{L}(M) d \lambda \text { and } Q=\frac{1}{2 \pi i} \int_{\Gamma} L_{\lambda}^{L}(M) d \lambda
$$

are projectors in the spaces $\mathfrak{U}$ and $\mathfrak{F}$, respectively. Here $\Gamma=\{\lambda \in \mathbb{C}:|\lambda|=r>a\}$.

Definition 2. The set $\mathfrak{P}$ is called the phase space of equation (5) if

1) for any $\left(u_{0}, u_{1}\right) \in T \mathfrak{P}(T \mathfrak{P}$ is the tangent bundle of $\mathfrak{P})$ there is a unique solution to problem (4), (5);

2) any solution $u=u(t)$ of equation (5) lies in $\mathfrak{P}$ as a trajectory.

Moreover, the notation $\left(u_{0}, u_{1}\right) \in T \mathfrak{P}$ should be understood as $u_{0} \in \mathfrak{P}$ and $u_{1} \in T_{u_{0}} \mathfrak{P}$.

Let ker $L \neq\{0\}$ and the operator $M$ be $(L, 0)$ bounded, then, by the splitting theorem [9], equation (7) can be reduced to an equivalent system of equations

$$
\left\{\begin{array}{c}
0=(\mathbb{I}-Q)(M+N)(u), \\
\ddot{u}^{1}=L_{1}^{-1} Q(M+N)(u),
\end{array}\right.
$$

where $u^{1}=P u$. Then the phase space $\mathfrak{P}$ of equation (5) is the set [10]

$$
\mathfrak{P}=\{u \in \mathfrak{U}:(\mathbb{I}-Q)(M+N)(u)=0\} .
$$

Thus, the existence of a unique local solution was proved. 
Every time when solving initial-boundary value problem for the Sobolev type equation by the Galerkin method, there arises an algebraic-differential system of the following form

$$
A \ddot{x}=F(x),
$$

where $x(t) \in \mathbb{R}^{m}, m \in \mathbb{N}, t \in[0, T]$, rank $A=k, k<m$. Transform system (6) to a first-order system introducing a new variable $y(t) \in \mathbb{R}^{2 m}$ and new matrix operators

$$
y(t)=\left(\begin{array}{l}
\dot{x}(t) \\
x(t)
\end{array}\right), \quad \bar{A}=\left(\begin{array}{ll}
A & \mathbb{O} \\
\mathbb{O} & \mathbb{I}
\end{array}\right), \quad \bar{F}=\left(\begin{array}{ll}
\mathbb{O} & F(\cdot) \\
\mathbb{I} & \mathbb{O}
\end{array}\right) .
$$

Then we get

$$
\begin{gathered}
\bar{A} \dot{y}=\bar{F}(y), \\
\operatorname{rank} \bar{A}=k+m .
\end{gathered}
$$

Split system (7) into two subsystems

$$
\begin{gathered}
0=\bar{F}^{0}(y), \\
\bar{Q} \bar{A} \dot{y}=\bar{F}^{1}(y),
\end{gathered}
$$

where $\bar{F}^{0}=\bar{P} \bar{Q} \bar{F}(y), \bar{F}^{1}(y)=(\mathbb{I}-\bar{P}) \bar{Q} \bar{F}(y)$, the matrix $\bar{Q}$ is obtained from the identity matrix by replacing the top rows with basis vectors of the left kernel (cokernel) of the matrix $\bar{A}, \bar{P}$ is a projector onto the left kernel of the matrix $\bar{Q} \bar{A}$. Therefore, the solution to system (7) lies in the set $\mathfrak{M}=\left\{y \in \mathbb{R}^{2 m}: \bar{F}^{0}(y)=0\right\}$.

Let the function $\bar{F} \in C^{s}, s \geq 1$, then the condition

$$
\operatorname{rank}\left(\bar{F}^{0}\right)_{y_{0}}^{\prime}=l,
$$

where $\left(\bar{F}^{0}\right)_{y_{0}}^{\prime}$ is the Jacobi matrix of the function $\bar{F}^{0}$ at the point $y_{0}$ has sense. Let there exist $y_{0} \in \mathfrak{M}$ such that condition (11) is satisfied in some neighborhood $O\left(y_{0}\right) \cap \mathfrak{M}$. Then $O\left(y_{0}\right) \cap \mathfrak{M}$ is a $C^{s}$-manifold and equation (9) can be reduced to the form

$$
\left(\bar{F}^{0}\right)_{y}^{\prime} \dot{y}=0, \quad y(0)=y_{0}
$$

Suppose that

$$
\operatorname{ker} \bar{Q} \bar{A} \cap \operatorname{ker}\left(\bar{F}^{0}\right)_{y_{0}}^{\prime}=\{0\} \text {, }
$$

in the neighborhood $O\left(y_{0}\right)$. Then the matrix $\bar{Q} A+\left(\bar{F}^{0}\right)_{y_{0}}^{\prime}$ is invertible in this neighborhood and the system (10), (12) is reduced to the form

$$
\dot{y}=\left(\bar{Q} \bar{A}+\left(\bar{F}^{0}\right)_{y_{0}}^{\prime}\right)^{-1} \bar{F}^{1}, \quad y(0)=y_{0}
$$

with a smooth right hand side.

By virtue of [13, Theorem 1], the following theorem holds:

Theorem 1. Let system (7) satisfy (8), $\bar{F} \in C^{s}, s \geq 1$ and let there be $y_{0} \in \mathfrak{M}$ such that in some neighborhood $O\left(y_{0}\right) \cap \mathfrak{M}$ condition (11) and (13) are satisfied. Then for some $t_{0}>0$ there is at least one solution $y \in C^{s}\left(0, t_{0} ; \mathfrak{M}\right)$ such that $y_{0}=y(0)$. The set $O\left(y_{0}\right) \cap \mathfrak{M}$ is a $C^{s}$-manifold of dimension $2 m-l \geq k$. For $s \geq 2$, the solution is unique. 


\section{Existence Theorem}

In some special cases of a nonlinear term in equation (1), one can not only answer the question about the existence and uniqueness of a solution, but also find this solution. Let us formulate and prove a theorem that answers the question on how to find a solution to $(1)-(3)$

Further, we need several function spaces such as $L^{4}(\Omega), H_{0}^{1}(\Omega)$. The operator $L$ : $H^{1}(\Omega) \rightarrow H^{-1}(\Omega)$ is given by formula

$$
\langle L u, v\rangle=\int_{\Omega}(\nabla u \nabla v+\lambda u v) d x .
$$

Denote $B=L^{4}(\Omega) \cap H_{0}^{1}(\Omega)$ and $D=H^{1}(\Omega) \cap \operatorname{coim} L\left(\right.$ where $\left.\operatorname{coim} L=H^{1}(\Omega) \ominus \operatorname{ker} L\right)$.

In addition, define spaces of distributions (functions with values in a Banach space) $L^{\infty}(0, T ; B)$ and $L^{\infty}\left(0, T ; L^{2}(\Omega)\right)$. Construct the conjugate spaces using the Dunford-Pettis theorem: $\left(L^{\infty}(0, T ; B)\right)^{*} \simeq L^{1}\left(0, T ; L^{\frac{4}{3}}(\Omega) \cup H^{-1}(\Omega)\right)$ and $\left(L^{\infty}(0, T ; D)\right)^{*} \simeq L^{1}\left(0, T ; D^{*}\right)$.

Let $\lambda_{k}$ be the eigenvalues of the homogeneous Dirichlet problem (2) for the Laplace operator, numbered nonincreasingly taking into account their multiplicity, and $\varphi_{k}$ be the corresponding eigenfunctions. In addition, the linear span of $\left\{\varphi_{1}, \varphi_{2}, \ldots, \varphi_{m}\right\}$ for $m \rightarrow \infty$ is dense in $B$ and orthonormal (in the sense of the inner product in $L^{2}(\Omega)$ ).

Theorem 2. Let $\lambda \in\left[\lambda_{1},+\infty\right), u_{0} \in B$ and $u_{1} \in D$ and $\left(u_{0}, u_{1}\right) \in T_{u_{0}} \mathfrak{P}$. Then there exists a solution to problem (1) - (3) $u=u(x, t)$ such that $u \in L^{\infty}(0, T ; B)$ and $\dot{u} \in L^{\infty}(0, T ; D)$.

Proof. The solution to problem (1) - (3) will be sought in the form of the Galerkin approximation

$$
u^{m}(t)=\sum_{k=1}^{m} a_{k}^{m}(t) \varphi_{k} .
$$

We need to find the coefficients $a_{k}^{m}(t)$ from the system of algebraic-differential equations

$$
\left\langle L \ddot{u}^{m}, \varphi_{k}\right\rangle-\alpha^{2}\left\langle\Delta u^{m}, \varphi_{k}\right\rangle+\left\langle\left(u^{m}\right)^{3}, \varphi_{k}\right\rangle=0, \quad 1 \leq k \leq m .
$$

Using the expansion of the initial functions in a series by basis functions, we obtain the initial conditions for the system of algebraic-differential equations (16)

$$
a_{k}^{m}(0)=\beta_{k}^{m}, \quad \dot{a}_{k}^{m}(0)=\gamma_{k}^{m}, \quad 1 \leq k \leq m,
$$

where $u_{0}^{m}=\sum_{k=1}^{m} \beta_{k}^{m} \varphi_{k} \rightarrow u_{0}$ in $B$ when $m \rightarrow \infty$, and $u_{1}^{m}=\sum_{k=1}^{m} \gamma_{k}^{m} \varphi_{k} \rightarrow u_{1}$ in $L^{2}(\Omega)$ when $m \rightarrow \infty$.

Apply Theorem 1 to problem (16), (17). Suppose $\lambda=\lambda_{1}$ then $\lambda_{1}$ is an eigenvalue of multiplicity 1 . Let's write out the matrices

$$
\begin{aligned}
& \bar{A}=\left(\begin{array}{ll}
\mathbb{O} & \mathbb{O} \\
\mathbb{O} & \mathbb{I}_{2 m-1}
\end{array}\right), \quad \bar{P}=\left(\begin{array}{ll}
\mathbb{I} & \mathbb{O} \\
\mathbb{O} & \mathbb{O}_{2 m-1}
\end{array}\right), \quad \mathbb{I}-\bar{P}=\left(\begin{array}{ll}
\mathbb{O} & \mathbb{O} \\
\mathbb{O} & \mathbb{I}_{2 m-1}
\end{array}\right), \quad \bar{Q}=\mathbb{I}_{2 m}, \\
& \bar{F}^{0}=\left(-\alpha^{2} a_{1}^{m}(t)-\left\langle\left(u^{m}\right)^{3}, \varphi_{1}\right\rangle\right), \quad \bar{F}^{1}=\left(\begin{array}{l}
-\alpha^{2} a_{l+1}^{m}(t)-\left\langle\left(u^{m}\right)^{3}, \varphi_{2}\right\rangle \\
\ldots \\
-\alpha^{2} a_{m}^{m}(t)-\left\langle\left(u^{m}\right)^{3}, \varphi_{m}\right\rangle \\
-\alpha^{2} \dot{a}_{1}^{m}(t)-\left\langle\left(\dot{u}^{m}\right)^{3}, \varphi_{1}\right\rangle \\
\cdots \\
-\alpha^{2} \dot{a}_{m}^{m}(t)-\left\langle\left(\dot{u}^{m}\right)^{3}, \varphi_{m}\right\rangle
\end{array}\right),
\end{aligned}
$$


moreover, $\mathfrak{M}=T \mathfrak{P}=\left\{y \in R^{2 m}: \bar{F}(y)=0\right\}$. Each element of the matrices $\bar{F}^{0}, \bar{F}^{1}$ is a third degree polynomial in the variables $a_{k}^{m}$, therefore $\bar{F}^{0} \in C^{\infty}$ and $\bar{F}^{1} \in C^{\infty}$. Thus, it is easy to check conditions (11) and (13) in a neighborhood contained in $\mathfrak{M}$. Thus, the conditions of Theorem 1 are satisfied, and hence there is a unique local solution $u^{m}=u^{m}(t, x), t \in\left[0, t^{m}\right]$.

Let's get a priori estimates. Multiplying equation (16) by $\dot{a}_{k}^{m}(t)(1 \leq k \leq m)$ and summing over $k$ from 1 to $m$, we get

$$
\left\langle L \ddot{u}^{m}, \dot{u}^{m}\right\rangle-\alpha^{2}\left\langle\Delta u^{m}, \dot{u}^{m}\right\rangle+\left\langle\left(u^{m}\right)^{3}, \dot{u}^{m}\right\rangle=0 .
$$

Introduce the norm in the space $D\left(L^{2}(\Omega)=\operatorname{coim} L \oplus \operatorname{ker} L\right)|\dot{u}|_{H^{1}}^{2}=\langle L \dot{u}, \dot{u}\rangle$. By the Courant principle, this norm is equivalent to the norm induced by the space $H^{1}(\Omega)$.

Using the self-adjointness of $L, \Delta$, we obtain $2\left\langle L \ddot{u}^{m}, \dot{u}^{m}\right\rangle=\frac{d}{d t}\left\langle L \dot{u}^{m}, \dot{u}^{m}\right\rangle, 2\left\langle\Delta u^{m}, \dot{u}^{m}\right\rangle=$ $-\frac{d}{d t}\left\langle\nabla u^{m}, \nabla u^{m}\right\rangle, 4\left\langle\left(u^{m}\right)^{3}, \dot{u}^{m}\right\rangle=\frac{d}{d t}\left\|u^{m}\right\|_{L^{4}(\Omega)}^{4}$, and equation (18) takes the form

$$
\frac{d}{d t}\left[\left|\dot{u}^{m}\right|_{H^{1}}^{2}+\alpha^{2}\left\langle\nabla u^{m}, \nabla u^{m}\right\rangle+\frac{1}{2}\left\|u^{m}\right\|_{L^{4}}^{4}\right]=0 .
$$

Integrate it on the segment $[0, t], t \leq t_{m}$

$$
\left|\dot{u}^{m}\right|_{H^{1}}^{2}+\alpha^{2}\left\|u^{m}\right\|_{H_{0}^{1}}^{2}+\frac{1}{2}\left\|u^{m}\right\|_{L^{4}}^{4} \leq\left|u_{1}^{m}\right|_{H^{1}}^{2}+\alpha^{2}\left|u_{0}^{m}\right|_{H_{0}^{1}}^{2}+\frac{1}{2}\left\|u_{0}^{m}\right\|_{L^{4}}^{4} .
$$

Since the right-hand side of the equality is bounded, the inequality

$$
\left|\dot{u}^{m}\right|_{H^{1}}^{2}+\alpha^{2}\left\|u^{m}\right\|_{H_{0}^{1}}^{2}+\frac{1}{2}\left\|u^{m}\right\|_{L^{4}}^{4} \leq C
$$

take place. The constant $C$ is independent of $t_{m}$ and therefore (20)holds for all $t \in[0, T]$.

Remark 1. Due to (20) the sequence of functions $\dot{u}^{m}$ is bounded in the space $L^{\infty}(0, T ; D)$, $u^{m}$ is bounded in $L^{\infty}(0, T ; B)$.

Since $u^{m}$ and $\dot{u}^{m}$ are bounded in the spaces $L^{\infty}(0, T ; B)$ and $L^{\infty}(0, T ; D)$, respectively, which are dual spaces to the separable Banach spaces $L^{1}\left(0, T ; H^{-1}(\Omega) \cup L^{4 / 3}(\Omega)\right)$ and $L^{1}\left(0, T ; D^{*}\right)$, one can choose ${ }^{*}$-weakly convergent subsequences $u^{m_{l}}$ and $\dot{u}^{m_{l}}$ such that $u^{m_{l}} \rightarrow u^{*}$-weakly in $L^{\infty}(0, T ; B)$, $\dot{u}^{m_{l}} \rightarrow \dot{u}^{*}$-weakly in $L^{\infty}\left(0, T ; L^{2}(\Omega)\right)$.

Moreover, $\dot{u}^{m_{l}}$ is understood as a generalized derivative in the space of distributions. Also from the boundedness of $\dot{u}^{m}$ in the space $L^{2}(0, T ; D)$ and $u^{m}$ in $L^{2}(0, T ; B)$ (by Remark 1 and the properties of Lebesgue spaces) it follows that $u^{m}$ is bounded in $H^{1}(C)$. By Lemma 5, we have $H^{1}(C) \subset L^{2}(C)$ (a completely continuous embedding). Therefore, we can assume that

$$
u^{m_{l}} \rightarrow u \text { strongly in } L^{2}(C) \text { and almost everywhere. }
$$

Since the sequence $\left(u^{m_{l}}\right)^{3}$ is bounded in the space $L^{\infty}\left(0, T ; L^{4 / 3}(\Omega)\right)$, it converges to some element $z$ of this space

$$
\left(u^{m_{l}}\right)^{3} \rightarrow z^{*} \text {-weakly in } L^{\infty}\left(0, T ; L^{4 / 3}(\Omega)\right)
$$


Corollary 1. Put $O=C, g_{l}=\left(u^{m_{l}}\right)^{3}, g=u^{3}$, then by Lemma 1, as well as (21) and (22) $z=u^{3}$.

Now we can go term by term to the limit in (16), setting $m_{l}=l$. Let $k$ be fixed and $l>k$, we get

$$
\left\langle L \ddot{u}^{l}, \varphi_{k}\right\rangle+\alpha^{2}\left\langle\nabla u^{l}, \nabla \varphi_{k}\right\rangle+\left\langle\left(u^{l}\right)^{3}, \varphi_{k}\right\rangle=0 .
$$

By Remark 1, we have the limit transitions

$$
\begin{aligned}
\left\langle\dot{u}^{l}, \varphi_{k}\right\rangle & \rightarrow\left\langle u, \varphi_{k}\right\rangle^{*} \text {-weakly in } L^{\infty}(0, T) ; \\
\left\langle\nabla u^{l}, \nabla \varphi_{k}\right\rangle & \rightarrow\left\langle\nabla u, \nabla \varphi_{k}\right\rangle{ }^{*} \text {-weakly in } L^{\infty}(0, T)
\end{aligned}
$$

and therefore

$$
\left\langle\ddot{u}^{l}, \varphi_{k}\right\rangle=\frac{d}{d t}\left\langle\dot{u}^{l}, \varphi_{k}\right\rangle \rightarrow\left\langle\ddot{u}, \varphi_{k}\right\rangle^{*} \text {-weakly in } L^{\infty}(0, T),
$$

and by Corollary 1

$$
\left\langle\left(u^{l}\right)^{3}, \varphi_{k}\right\rangle \rightarrow\left\langle u^{3}, \varphi_{k}\right\rangle^{*} \text {-weakly in } L^{\infty}(0, T) .
$$

Thus, from (23) we deduce

$$
\frac{d^{2}}{d t^{2}}\left\langle L u, \varphi_{k}\right\rangle+\alpha^{2}\left\langle\nabla u, \nabla \varphi_{k}\right\rangle+\left\langle u^{3}, \varphi_{k}\right\rangle=0
$$

In view of the density of the system of functions $\left\{\varphi_{k}\right\}_{k=1}^{m}$ in the space $B$ for $m \rightarrow \infty$, and the arbitrariness of the choice of $\varphi_{k}$, the equality holds for an arbitrary $v \in B$

$$
\frac{d^{2}}{d t^{2}}\langle L u, v\rangle+\alpha^{2}\langle\nabla u, \nabla v\rangle+\left\langle u^{3}, v\right\rangle=0 .
$$

Due to the expansion of the initial values into a series $u_{l}(0)=u_{l}^{0} \rightarrow u_{0}$ in $H^{1}(\Omega)$ and $u_{l}(0) \rightarrow u(0)$ in $B$, therefore $u(0)=u_{0}$.

By Remark 1

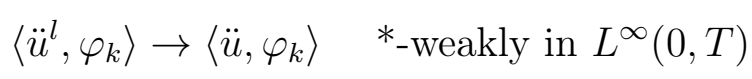

and, therefore, taking into account Lemma 3, we obtain

$$
\left.\left\langle\dot{u}^{l}(0), \varphi_{k}\right\rangle \rightarrow\left\langle\dot{u}(t), \varphi_{k}\right\rangle\right|_{t=0}=\left\langle\dot{u}(0), \varphi_{k}\right\rangle
$$

On the other hand, due to the expansion of the initial values into a series

$$
\left\langle\dot{u}^{l}(0), \varphi_{k}\right\rangle \rightarrow\left\langle u_{1}, \varphi_{k}\right\rangle
$$

Thus,

$$
\left\langle\dot{u}(0), \varphi_{k}\right\rangle=\left\langle u_{1}, \varphi_{k}\right\rangle, \quad \forall k .
$$

Therefore the function $u=u(x, t)$ satisfies the equation and initial conditions, i.e. it is the solution of $(1)-(3)$. 


\section{Uniqueness Theorem}

Theorem 3. Under the conditions of Theorem 1 and Lemma 5, the solution to problem (1) - (3) is unique.

Proof. Let $u$ and $v$ be two different solutions to problem (1) - (3), denote $w=u-v$. Then equation (1) takes the form

$$
(\lambda-\Delta) w_{t t}-\alpha^{2} \Delta w=v^{3}-u^{3},
$$

and the Cauchy conditions become homogeneous

$$
w(x, 0)=0, \quad w_{t}(x, 0)=0, \quad w \in \Omega .
$$

Similarly to the previous section, equation (26) is reduced to the form (19). However, instead of the standard norms of the spaces $H^{1}$ and $H_{0}^{1}$, their equivalent, defined by the rule $|\dot{w}|_{H^{1}}^{2}=\langle L \dot{w}, \dot{w}\rangle,|w|_{H_{0}^{1}}^{2}=\left\langle\alpha^{-2} \nabla w, \nabla w\right\rangle$ is used.

$$
\frac{d}{d t}\left[|\dot{w}|_{H^{1}}^{2}+|w|_{H_{0}^{1}}^{2}\right]=2\left\langle v^{3}-u^{3}, \dot{w}^{m}\right\rangle
$$

Obviously

$$
2\left\langle v^{3}-u^{3}, \dot{w}^{m}\right\rangle \leq 6 \int_{\Omega} \sup \left(|u|^{2},|v|^{2}\right)|w||\dot{w}| d x .
$$

Using the Holder's inequality, we estimate the right-hand side of the previous inequality

$$
\int_{\Omega} \sup \left(|u|^{2},|v|^{2}\right)|w||\dot{w}| d x \leq C\left(\left\||u|^{2}\right\|_{L^{4}}+\left\||v|^{2}\right\|_{L^{4}}\right)\|w\|_{L^{4}}\|\dot{w}\|_{L^{2}},
$$

further, using embedding theorems and the properties of the norm, we obtain

$$
\begin{gathered}
\left.C\left(\left\||u|^{2}\right\|_{L^{4}}+\left\||v|^{2}\right\|_{L^{4}}\right)\|w\|_{L^{4}}\left|\dot{w} \|_{L^{2}} \leq C\left(|u|_{L^{4}}^{2}+|v|_{L^{4}}^{2}\right)\right| w\right|_{H_{0}^{1}}|\dot{w}|_{H^{1}} \leq \\
\leq C|w|_{H_{0}^{1}}|\dot{w}|_{H^{1}} \leq 2 C\left(|w|_{H_{0}^{1}}^{2}+|\dot{w}|_{H^{1}}^{2}\right) .
\end{gathered}
$$

Then (28) leads to the inequality

$$
\left[|\dot{w}|_{H^{1}}^{2}+|w|_{H_{0}^{1}}^{2}\right] \leq 2 C \int_{0}^{t}\left(|w|_{H_{0}^{1}}^{2}+|\dot{w}|_{H^{1}}^{2}\right) d s
$$

whence, by Lemma 4 , we have the equality $|\dot{w}|_{H^{1}}^{2}+|w|_{H_{0}^{1}}^{2}=0$. Therefore $w \equiv 0$ and $u \equiv v$.

\section{Conclusion}

Instead of the Cauchy condition (3) for problem (1) - (3), the Showalter-Sidorov condition

$$
L\left(u(0)-u_{0}\right)=0, \quad L\left(\dot{u}(0)-u_{1}\right)=0
$$


can be posed. Condition (29) is a natural generalization of the Cauchy conditions for Sobolev type equations [24]. By construction of the conditions (29), the existence and uniqueness theorem has less conditions.

Corollary 2. Let $\lambda \in\left[\lambda_{1},+\infty\right), u_{0} \in B$ and $u_{1} \in D$. Then there is a unique solution to problem (1), (2), (29) $u=u(x, t)$ such that $u \in L^{\infty}(0, T ; B)$ and $\dot{u} \in L^{\infty}(0, T ; D)$.

The number of terms in (15) should be chosen so that the linear span covers the kernel of the operator $L$.

\section{References}

1. Bogolubsky I.L. Some Examples of Inelastic Soliton Interaction. Computational Physics Communications, 1977, vol. 13, no. 2, pp. 49-55. DOI: 10.1016/0010-4655(77)90009-1

2. Clarkson P.A., Leveque R.J., Saxton R., Solitary Wave Interactions in Elastic Rods. Studies in Applied Mathematics, 1986, vol. 75, no. 1, pp. 95-122. DOI: 10.1002/sapm198675295

3. Wang Shubin, Chen Guowang. Small Amplitude Solutions of the Generalized IMBq Equation. Journal Mathematical Analysis Applied, 2002, vol. 274, issue 2, pp. 846-866. DOI: 10.1016/S0022-247X(02)00401-8

4. Arkhipov D.G., Khabakhpashev G.A. New Equation for the Description of Inelastic Interaction of Nonlinear Localized Waves in Dispersive Media. Journal of Experimental and Theoretical Physics Letters, 2011, vol. 93, no. 8, pp. 423-426. DOI: $10.1134 /$ S0021364011080042

5. Zhang Weiguo, Ma Wenxiu. Explicit Solitary-Wave Solutions to Generalized PochhammerChree Equations. Applied Mathematics and Mechanics, 1999, vol. 20, no. 6, pp. 625-632. DOI: $10.1007 /$ bf02464941

6. Runzhang Xu, Yacheng Liu. Global Existence and Blow-up of Solutions for Generalized Pochhammer-Chree Equations. Acta Mathematica Scientia, 2010, vol. 30, issue 5, pp. 1793-1807. DOI: 10.1016/S0252-9602(10)60173-7

7. Showalter R.E. Sobolev Equations for Nonlinear Dispersive Systems. Applicable Analysis, 1977, vol. 7, issue 4, pp. 279-287. DOI: 10.1080/00036817808839202

8. Sviridyuk G.A., Sukacheva T.G. [Phase Spaces of a Class of Operator Equations]. Differential Equations, 1990, vol. 26, no. 2, pp. 250-258. (in Russian)

9. Sviriduyk G.A., Zamyshlyaeva A.A. The Phase Space of a Class of Linear Higher Order Sobolev Type Equations. Differential Equations, 2006, vol. 42, no. 2, pp. 269-278. DOI: $10.1134 /$ S0012266106020145

10. Zamyshlyaeva A.A., Bychkov E.V. The Cauchy Problem for the Sobolev Type Equation of Higher Order. Bulletin of the South Ural State University. Series: Mathematical Modelling, Programming and Computer Software, 2018, vol. 11, no. 1, pp. 5-14. DOI: $10.14529 / \mathrm{mmp} 180101$

11. Sviridyuk G.A., Zamyshlyaeva A.A. The Phase Spaces of a Class of Linear HigherOrder Sobolev Type Equations. Differential Equations, 2006, vol. 42, no. 2, pp. 269-278. DOI: $10.1134 /$ S0012266106020145

12. Zamyshlyaeva A.A. The Higher-Order Sobolev-Type Models. Bulletin of the South Ural State University. Series: Mathematical Modelling, Programming and Computer Software, 2014, vol. 7, no. 2, pp. 5-28. (in Russian) DOI: 10.14529/mmp140201

13. Sviridyuk G.A. [On the Solvability of a Singular System of Ordinary Differential Equations]. Differential Equations, 1987, vol. 23, no. 9, pp. 1637-1639. (in Russian) 
14. Chistyakov V.F., Chistyakova E.V. Linear Differential-Algebraic Equations Perturbed by Volterra Integral Operators. Differential Equations, 2017, vol. 53., no. 10, pp. 1274-1287. DOI: $10.1134 /$ S0012266117100044

15. Zamyshlyaeva A.A., Lut A.V. Numerical Investigation of the Boussinesq-Löve Mathematical Models on Geometrical Graphs. Bulletin of the South Ural State University. Series: Mathematical Modelling, Programming and Computer Software, 2017, vol. 10, no. 2, pp. 137-143. DOI: $10.14529 / \mathrm{mmp} 170211$

16. Shafranov D.E., Kitaeva O.G. The Barenblatt-Zheltov-Kochina Model with the ShowalterSidorov Condition and Additive "White Noise" in Spaces of Differential Forms on Riemannian Manifolds without Boundary. Global and Stochastic Analysis, 2018, vol. 5, no. 2, pp. 145-159.

17. Manakova N. A., Bogatyreva E.A. [On a Solution of the Dirichlet-Cauchy Problem for the Barenblatt-Gilman Equation]. The Bulletin of Irkutsk State University. Series: Mathematics, 2014, vol. 7, pp. 52-60. (in Russian)

18. Bogatyreva E.A., Manakova N.A. Numerical Simulation of the Process of Nonequilibrium Counterflow Capillary Imbibition. Computational Mathematics and Mathematical Physics, 2016, vol. 56, no. 1, pp. 132-139. DOI: 10.7868/S0044466916010087

19. Sveshnikov A.G., Al'shin A.B., Korpusov M.O., Pletner Yu.D. Lineynyye $i$ nelineynyye uravneniya Sobolevskogo tipa [Linear and Nonlinear Sobolev Type Equation]. Moscow, Fizmatlit, 2007. (in Rusian)

20. Keller A.V. On the Computational Efficiency of the Algorithm of the Numerical Solution of Optimal Control Problems for Models of Leontieff Type. Journal of Computational and Engineering Mathematics, 2015, vol. 2, no. 2. pp. 39-59. DOI: 10.14529/jcem150205

21. Lions J.L. Sur Quelques Methodes de Resolution des Problemes aux Limites non Linears. Paris, Dunod, Gauthier Villars, 1969. (in French)

22. Hartman P. Ordinary Differential Equations. New York, London, Sydney, John Wiley and Sons, 1964.

23. Triebel H. Interpolation Theory, Function Spaces, Differential Operators. Berlin, VEB Deutscher Verlag der Wissenschaften, 1978. (in German)

24. Sviridyuk G.A., Zagrebina S.A. The Showalter-Sidorov Problem as a Phenomena of the Sobolev-Type Equations. The Bulletin of Irkutsk State University. Series: Mathematics, 2010, vol. 3, no. 1, pp. 104-125. (in Russian)

Received August 19, 2020

\section{АНАЛИТИЧЕСКОЕ ИССЛЕДОВАНИЕ МАТЕМАТИЧЕСКОЙ МОДЕЛИ РАСПРОСТРАНЕНИЯ ВОЛН НА МЕЛКОЙ ВОДЕ МЕТОДОМ ГАЛЕРКИНА}

E.B. Бычков, Южно-Уральский государственный университет, г. Челябинск, Российская Федерация

Рассматривается начально-краевая задача для модифицированного уравнения Буссинеска (уравнения IMBq). Уравнение часто используется для описания распро- 
странения волн на мелкой воде при условии сохранения массы в слое и с учетом капиллярных эффектов. Кроме того, оно используется при исследовании ударных волн. Модифицированное уравнение Буссинеска относится к уравнениям соболевского типа. Ранее, используя теорию относительно p-ограниченных операторов было доказано существование и единственность решения начально-краевой задачи. В данной работе мы докажем, что решение, построенное методом Галеркина по системе ортонормированных собственных функций однородной задачи Дирихле для оператора Лапласа, сходится *-слабо к точному решению. Опираясь на метод компактности и неравенство Гронуолла доказано существование и единственность решений задачи Коши - Дирихле и задачи Шоуолтера - Сидорова - Дирихле для модифицированного уравнения Буссинеска.

Ключевые слова: модифищированное уравнение Буссинеска; уравнения соболевского типа; начально-краевая задача; метод Галеркина; *-слабая сходимость.

\section{Литература}

1. Bogolubsky, I.L. Some Examples of Inelastic Soliton Interaction / I.L. Bogolubsky // Computational Physics Communications. - 1977. - V. 13, № 2. - P. 49-55.

2. Clarkson, P.A. Solitary Wave Interactions in Elastic Rods / P.A. Clarkson, R.J. Leveque, R. Saxton // Studies in Applied Mathematics. - 1986. - V. 75, № 1. - P. 95-122.

3. Shubin Wang. Small Amplitude Solutions of the Generalized IMBq Equation / Shubin Wang, Guowang Chen // Journal Mathematical Analysis Applied. - 2002. - V. 274. - P. 846-866.

4. Архипов, Д.Г. Новое уравнение для описания неупругого взаимодействия нелинейных локализованных волн в диспергирующих средах / Д.Г. Архипов, Г.А. Хабахпашев // Письма в Журнал экспериментальной и теоретической физики. - 2011. - Т. 93, № 8. C. $469-472$.

5. Weiguo Zhang. Explicit Solitary-Wave Solutions to Generalized Pochhammer-Chree Equations / Weiguo Zhang, Wenxiu Ma // Applied Mathematics and Mechanics. - 1999. V. 20, № 6. - P. 625-632.

6. Runzhang Xu Global Existence and Blow-Up of Solutions for Generalized PochhammerChree Equations / Xu Runzhang, Liu Yacheng // Acta Mathematica Scientia. - 2010. V. 30, issue 5. - P. 1793-1807.

7. Showalter, R.E. Sobolev Equations for Nonlinear Dispersive Systems / R.E. Showalter // Applicable Analysis. - 1977. - V. 7, issue 4. - P. 279-287.

8. Свиридюк, Г.А. Фазовые пространства одного класса операторных полулинейных уравнений типа Соболева / Г.А. Свиридюк, Т.Г. Сукачева // Дифференциальные уравнения. - 1990. - Т. 26, № 2. - С. 250-258.

9. Свиридюк, Г.А. Фазовые пространства одного класса линейных уравнений соболевского типа высокого порядка / Г.А. Свиридюк, А.А. Замышляева // Дифференциальные уравнения. - 2006. - Т. 42, № 2. - С. 252-260.

10. Zamyshlyaeva, A.A. The Cauchy Problem for the Sobolev Type Equation of Higher Order / A.A. Zamyshlyaeva, E.V. Bychkov // Вестник ЮУрГУ. Серия: Математическое моделирование и программирование. - 2018. - Т. 11, № 1. - С. 5-14.

11. Свиридюк, Г.А. Фазовые пространства одного класса линейных уравнений соболевского типа высокого порядка / Г.А. Свиридюк, А.А. Замышляева // Дифференциальные уравнения. -2006 . - Т. 42, № 2. - С. 252-260.

12. Замышляева, А.А. Математические модели соболевского типа высокого порядка / А.А. Замышляева // Вестник ЮУрГУ. Серия: Математическое моделирование и программирование. - 2014. - Т. 7, № 2. - С. 5-28. 
13. Свиридюк, Г.А. О разрешимости сингулярной системы обыкновенных дифференциальных уравнений / Г.А. Свиридюк // Дифференциальные уравнения. - 1987. - Т. 23, № 9. C. $1637-1639$.

14. Чистяков, В.Ф. Линейные дифференциально-алгебраические уравнения с возмущениями в виде интегральных операторов Вольтерры / В.Ф. Чистяков, Е.В. Чистякова // Дифференциальные уравнения. - 2017. - Т. 53, № 10. - С. 1309.

15. Zamyshlyaeva, A.A. Numerical Investigation of the Boussinesq - Love Mathematical Models on Geometrical Graphs / A.A. Zamyshlyaeva, A.V. Lut // Вестник ЮУрГУ. Серия: Математическое моделирование и программирование. - 2017. - Т. 10, № 2. - С. 137-143.

16. Shafranov, D.E., The Barenblatt - Zheltov - Kochina Model with the Showalter - Sidorov Condition and Additive «White Noise» in Spaces of Differential Forms on Riemannian Manifolds without Boundary / D.E. Shafranov, O.G. Kitaeva// Global and Stochastic Analysis. - 2018. - V. 5, № 2. - P. 145-159.

17. Манакова, Н.А. О решении задачи Коши - Дирихле для уравнения Баренблатта - Гильмана / Н.А. Манакова, Е.А. Богатырева // Известия Иркутского государственного университета. Серия: Математика. - 2014. - Т. 7. - С. 52-60.

18. Манакова, Н.А. Численное моделирование процесса неравновесной противоточной капиллярной пропитки / Н.А. Манакова, Е.А. Богатырева // Журнал вычислительной математики и математической физики. - 2016. - Т. 56, № 1. - С. 125-132.

19. Свешников, А.Г. Линейные и нелинейные уравнения соболевского типа / А.Г. Свешников, А.Б. Альшин, М.О. Корпусов, Ю.Д. Плетнер. - М.: ФИЗМАТЛИТ, 2007.

20. Keller, A.V. On the Computational Efficiency of the Algorithm of the Numerical Solution of Optimal Control Problems for Models of Leontieff Type / A.V. Keller // Journal of Computational and Engineering Mathematics. - 2015. - V. 2, № 2. - P. 39-59.

21. Лионс, Ж.-Л. Некоторые методы решения нелинейных краевых задач / Ж.-Л. Лионс. М.: Мир, 1972.

22. Хартман, Ф. Обыкновенные дифференциальные уравнения / Ф. Хартман. - М.: Мир, 1970.

23. Трибель, Х. Теория интерполяции. Функциональные пространства. Дифференциальные операторы / Х. Трибель. - М.: Мир, 1980.

24. Свиридюк, Г.А. Задача Шоуолтера - Сидорова как феномен уравнений соболевского типа / Г.А. Свиридюк, С.А. Загребина // Известия Иркутского государственного университета. Серия: Математика. - 2010. - Т. 3, № 1. - С. 104-125.

Евгений Викторович Бычков , кандидат физико-математических наук, доцент, кафедра «Уравнения математической физики», Южно-Уральский государственный университет (г. Челябинск, Российская Федерация), bychkovev@susu.ru.

Поступила в редакиию 19 августа 2020 г. 